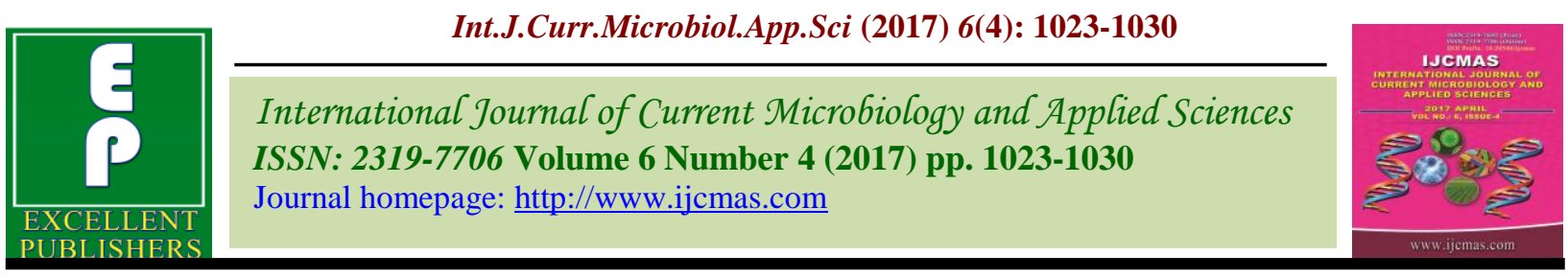

Original Research Article https://doi.org/10.20546/ijcmas.2017.604.127

\title{
Isolation and Identification of Lactic Acid Bacteria and their Exploration in Non-Dairy Probiotic Drink
}

\author{
Mamta Thakur $^{1 *}$, H.W. Deshpande ${ }^{2}$ and M.A. Bhate ${ }^{3}$ \\ ${ }^{1}$ Department of Food Trade and Business Management, College of Food Technology, Vasantrao \\ Naik Marathwada Krishi Vidyapeeth, Parbhani - 431402 (Maharashtra) India \\ ${ }^{2}$ Department of Food and Industrial Microbiology, College of Food Technology, Vasantrao Naik \\ Marathwada Krishi Vidyapeeth, Parbhani - 431402 (Maharashtra) India \\ ${ }^{3}$ Department of Microbiology, Shivaji College, Parbhani- 431402 (Maharashtra) India \\ *Corresponding author
}

A B S T R A C T

\begin{tabular}{|l|}
\hline Key w o r d s \\
Biochemical tests, \\
Carbohydrate \\
fermentation, \\
Identification, Lactic \\
acid bacteria, Probiotic \\
pomegranate drink.
\end{tabular}

Lactic acid bacteria were isolated from the curd and pickle samples. The morphological and biochemical characteristics and sugar fermentation pattern were employed to identify lactic acid bacteria. The isolates from both curd and pickle were identified as rods/bacilli. Both the isolates were Gram positive, nonmotile, catalase negative and exhibited negative pattern of citrate utilization, $\mathrm{H}_{2} \mathrm{~S}$ formation, indole production, oxidase test, urease activity, $\mathrm{NH}_{3}$ production from arginine and VP reaction. Phenotypic methods, especially determination of sugar fermentation patterns, were found to be more effective than biochemical tests for the differentiation of bacilli isolates at the strain level using Bergey's Manual of Determinative Bacteriology. Fermentation profile of nine different sugars was taken as base for identifying isolates. The isolate from curd was identified to be $L$. delbrueckii ssp. bulgaricus while other was Lactobacillus plantarum. The genotypic identification also supported the results of phenotypic methods. Thus identified cultures were then incorporated in pasteurized pomegranate juice and allowed to ferment for preparing the drink with optimum level of probiotic culture.

\section{Introduction}

Industrialization of biotechnological transformation of the foodstuffs has increased the economic importance of lactic acid bacteria (LAB) because they play a crucial role in the sensorial and safety aspects of fermented foods. Further, interest in the use of LAB has significantly increased globally due to their nutraceutical role (Leisner et al., 1999). Lactic acid bacteria are widely distributed in nature and able to promote fermentation by utilization of food nutrients and produce a variety of substances like organic acids, aromatic compounds, health benefit-substances, etc (O'Shea et al., 2011). LAB is characterized as gram-positive, nonmotile, non sporulating bacteria that produce lactic acid as a major product of fermentative metabolism (Pelinescu et al., 2009). They are 
Generally Recognized as Safe and can be used well for medical and veterinary applications (Hoque et al., 2010). Some species of the genus Lactobacillus, Lactococcus, Pediococcus and Leuconostoc are included in this group.

To comprehend the emerging requirement of probiotics, many studies focused on isolating the probiotic potential LAB from different resources of fermented foods (Kalui et al., 2009).

Dairy is a very nutritious substrate for LAB but expanding trend of vegan lifestyles; the issues of lactose intolerance and demand for low-fat and low-cholesterol foods have created a need for non-dairy probiotic products (Ranadheera et al., 2010).

Fresh fruits and vegetables are considered good matrices and can provide ideal substrates for probiotics, since they contain minerals, vitamins, antioxidants and fibers and do not contain any dairy allergens (Luckow and Delahunty, 2004). Pomegranate (Punica granatum L.), known to be a superfruit, has health-promoting properties with antimicrobial, anticancer, antioxidant and antimutagenic effects (Negi et al., 2003).

In the present investigation, lactic acid bacteria were the isolated and identified from curd and pickle in order to use them as starter for developing probiotic drink based on pomegranate juice.

\section{Materials and Methods}

The curd, mango pickle and freshly harvested pomegranate fruits (var. Bhagwa) were procured from local market of Parbhani (Maharashtra) India. Pomegranate juice was prepared by blending the juicy arils in the domestic mixer. Its total soluble solids was maintained to $13^{\circ} \mathrm{Bx}$ and stored at $4^{\circ} \mathrm{C}$ before use.

\section{Isolation of lactic acid bacteria}

After, weighing and homogenization of each sample, 1:10 dilution was subsequently made using sterile normal saline $(0.85 \%)$ followed by making a 10 fold serial dilution. The 0.1 $\mathrm{mL}$ from each dilution was then sub-cultured aseptically into MRS (deMan Rogosa and Sharpe) agar (Guessas and Kihal, 2004) using pour plate technique, all plates were then incubated at $37^{\circ} \mathrm{C}$ for $24-48$ hours in anaerobic condition to provide an optimal environmental for growing Lactobacilli.

Only the Gram positive and rod shape isolates were then purified by streak plating using the MRS medium. After several subcultures, finally the single colony of LAB was isolated by observing their colony morphology and Gram staining, catalase and motility test. The culture was kept in MRS agar slant and stored at $4{ }^{\circ} \mathrm{C}$ for long term storage (Hawaz, 2014).

\section{Identification of lactic acid bacteria}

The isolated colony was identified using Gram staining, biochemical tests and carbohydrate fermentation profile (Chris et al., 2006).

\section{Biochemical identification}

Strains with Gram positive, catalase negative and no motility were further used for identification (Sharpe, 1979). Utilization of citrate, hydrolysis of arginine, production of hydrogen sulfide and indole were determined (Samelis et al., 1994). Further, methyl reduction test, oxidase test, urease test and VP reaction were also performed.

\section{Carbohydrate fermentation profile}

All the strains were also tested for fermentation of sugars viz. glucose, fructose, lactose, sucrose, maltose, mannitol, salicin, 
agarose and sorbitol by adding the specific sugar to the basal carbohydrate media. Acid production was indicated by a change in color and gas production was detected by observation of gas collection in the inverted Durham tubes (Tserovska et al., 2002).

Molecular identification of lactic acid bacteria

The isolated bacteria were sent to Agharkar Research Institute, Pune where strains of promising probiotic LAB were identified by 16S rRNA multiplex PCR analysis (Markiewicz and Biedrzycka, 2005). This was in confirmation to the morphological, biochemical and carbohydrate fermentation tests performed in Department of Food and Industrial Microbiology, College of Food Technology, V.N.M.K.V., Parbhani (Maharashtra) India.

\section{Preparation of starter culture}

L. plantarum and L. bulgaricus was cultivated separately in the MRS broth for $24-\mathrm{h}$ at $37^{\circ} \mathrm{C}$. To obtain the biomass, $10 \mathrm{~mL}$ of the separately cultivated MRS broths were mixed in equal proportion (1:1) and centrifuged at $4000 \mathrm{rpm}$ for $10 \mathrm{~min}$. The obtained biomass was washed with sterile saline solution twice to remove the residual MRS media. Thus, inoculum was prepared.

It was then introduced into pasteurized pomegranate juice $(100 \mathrm{~mL})$ for making it $10 \%$ concentration of probiotics. The inoculated juice was then incubated at $37^{\circ} \mathrm{C}$ for $24 \mathrm{~h}$ and was treated as starter culture for preparation of final drink.

\section{Preparation of probiotic pomegranate drink}

Above prepared starter culture $(10 \mathrm{~mL})$ was then added to the pasteurized pomegranate juice $(100 \mathrm{~mL})$ to obtain $10 \%$ inoculation. It was allowed to ferment in incubator at $37^{\circ} \mathrm{C}$ for $7 \mathrm{~h}$. After incubation, the drink was kept at refrigeration temperature for future use.

\section{Microbial analysis of probiotic pomegranate drink}

The viable count of mixed culture was determined by the standard plate count method using Man-Rogosa-Sharpe agar (MRS agar) and the results were expressed as $\mathrm{CFU} / \mathrm{ml}$ juice. The yeast and mold count of drink was determined using potato dextrose agar medium. The coli-form and basically $E$. coli are the indicator microbes of water contamination by feces. The coli-form gives red pink color colonies on the MacConkey agar (Chris et al., 2006).

\section{Results and Discussion}

\section{Isolation of lactic acid bacteria}

Bacteria were isolated with MRS agar media at $37^{\circ} \mathrm{C}$ under anaerobic conditions for 48 hours. The isolated colonies from curd were named as Isolate A and from pickle were as Isolate B (Fig. 1). The isolated colonies were then screened for further identification.

\section{Identification of lactic acid bacteria species}

The complete findings of morphological and biochemical characterization of the isolates are presented in table 1 .

Both the isolates gave purple/violet color with staining showing Gram positive nature (Fig. 2). Because Gram positive cell wall contain thick layer of peptidoglycan with numerous teichoic acid cross linking which resists the decolorization, thus remaining purple in color. The isolates coming from MRS plates were all rods with long and rounded ends. They appeared mostly as a chain of 3-4 cells or single or in pairs. 
The hanging drop method showed that the bacteria were non-motile which one of the unique characteristics of Lactobacilli. This might be due to the absence of unique propeller-like flagella in Lactobacilli responsible for motility. Similar observations were found by Forouhandeh (2010) in the isolation of Lactobacillus species from traditional cheeses and yogurts of Basmej Zone in Iran.

Table.1 Morphological and biochemical characterization of the isolates

\begin{tabular}{|c|c|c|c|}
\hline \multirow{2}{*}{ S. No. } & \multirow{2}{*}{ Characteristics } & \multicolumn{2}{|l|}{ Isolates } \\
\hline & & A & $\mathbf{B}$ \\
\hline A. & Morphological tests & & \\
\hline 1 & Gram staining & + & + \\
\hline 2 & Shape & $\begin{array}{l}\text { Long rods, pair } \\
\text { or chains }\end{array}$ & $\begin{array}{l}\text { Long rods, } \\
\text { single, pair or } \\
\text { chains }\end{array}$ \\
\hline 3 & Motility & - & - \\
\hline B. & Biochemical tests & & \\
\hline 1 & Catalase & - & - \\
\hline 2 & Citrate test & - & - \\
\hline 3 & $\mathrm{NH}_{3}$ from arginine & - & - \\
\hline 4 & Hydrogen sulphide production & - & - \\
\hline 5 & Indole production & - & - \\
\hline 6 & Methyl red reaction & + & + \\
\hline 7 & Oxidase test & - & - \\
\hline 8 & Urease test & - & - \\
\hline 9 & Voges Proskauer (VP) Reaction & - & - \\
\hline
\end{tabular}

Table.2 Carbohydrate utilization pattern of isolates

\begin{tabular}{clll}
\hline \multirow{2}{*}{ S. No. } & Suagr(s) & \multicolumn{3}{c}{ Isolates } \\
\cline { 2 - 4 } & Glucose & A & B \\
\hline 1 & Glucose (Gas) & + & + \\
3 & Fructose & + & + \\
4 & Sucrose & - & + \\
5 & Lactose & + & + \\
6 & Maltose & - & + \\
7 & Mannitol & - & + \\
8 & Sorbitol & - & + \\
9 & Arabinose & - & + \\
10 & Salicin & - & + \\
\hline
\end{tabular}



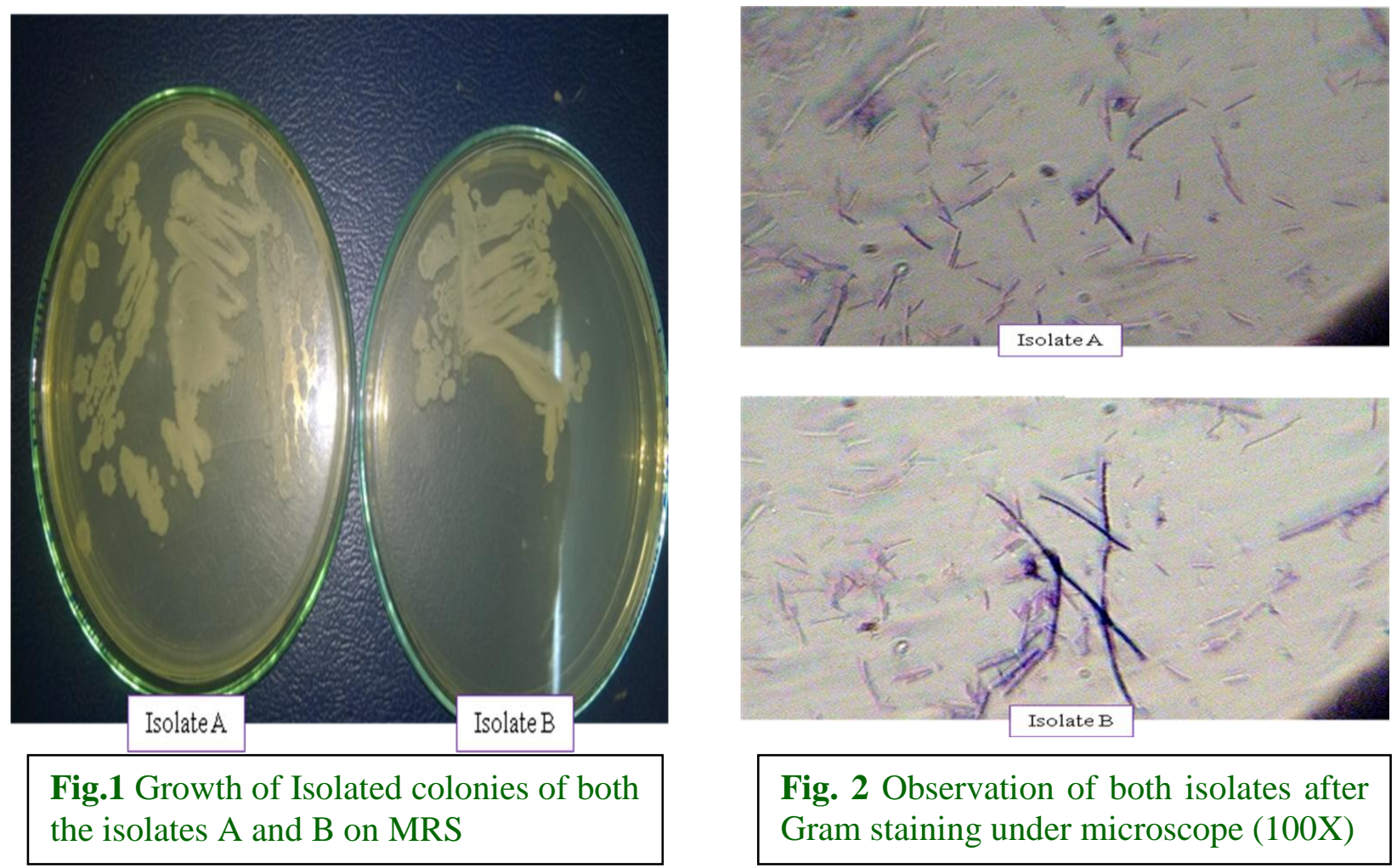

Fig. 2 Observation of both isolates after Gram staining under microscope (100X)

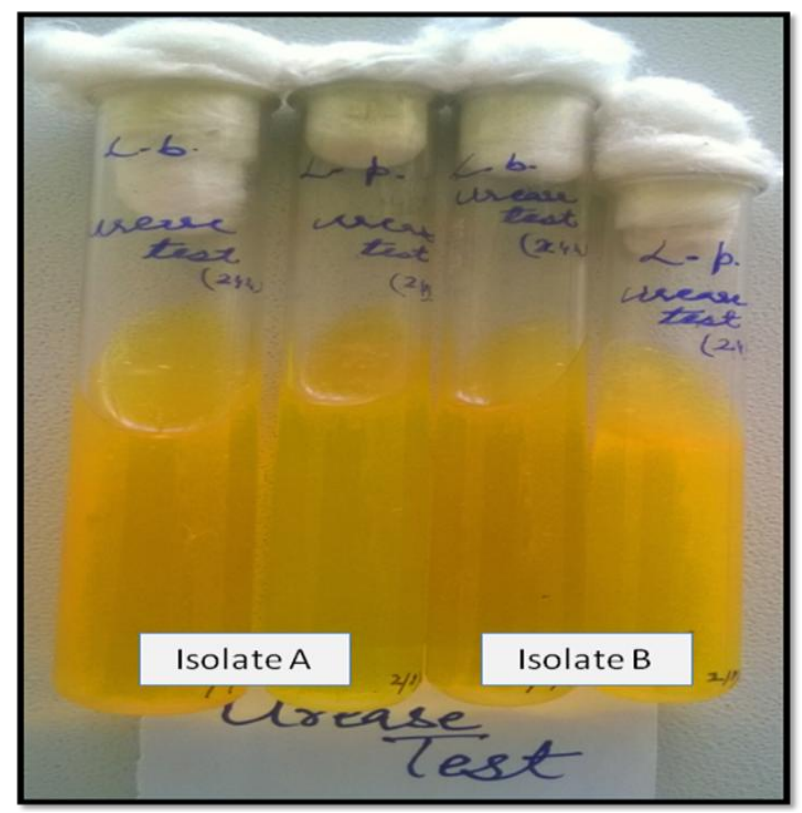

Fig.3 Orange yellow color of Urease media showing negative urease test for both isolates 
Table 3 Microbial analysis of probiotic pomegranate drink

\begin{tabular}{lll}
\hline S. No. & Parameters & Observations \\
\hline 1 & Total plate count $(\mathrm{CFU} / \mathrm{mL})$ & $6.5 \times 10^{9}$ \\
2 & Yeast and mold count $(\mathrm{CFU} / \mathrm{mL})$ & ND \\
3 & Coli-form count $(\mathrm{MPN} / \mathrm{mL})$ & ND \\
\hline
\end{tabular}

-Each value is an average of three determinations

ND: not detected

No bubble was observed indicating that the isolated bacteria are catalase negative and could not mediate the decomposition of $\mathrm{H}_{2} \mathrm{O}_{2}$ to produce oxygen. It is well known that Lactobacillus is catalase negative. Similar results are reported by Mithun et al., (2015).

For the citrate utilization test, both the isolates were not able to use citrate as the sole source of carbon and energy and couldn't lead to the production of sodium bicarbonate as well as ammonia. Thus, the results of citrate test showed the absence of formation of blue color in both the test tube.

In the $\mathrm{H}_{2} \mathrm{~S}$ production test, no blackening of media was observed in both the isolates. The organisms were not able to reduce the sulphur compounds to the sulphide because sulphide compounds would then combine with iron compounds to produce $\mathrm{FeS}$, a black precipitate.

The isolates under study didn't possess the characteristic of producing indole from tryptophan by the means of "tryptophanase". Therefore, addition of the Kovac's reagent didn't lead to the formation of a deep red color on the surface layer; it remained yellow as it was initially (Chris et al., 2006).

In the oxidase test, the bacterial cultures were not able to carry out the oxidation of colorless reagent, tetramethyl p-phenylene diamene dihydrochloride, to yield the purple compound. This might be due to the fact that the isolates didn't possess the cytochrome c (which means isolates might be anaerobic organism) that enables them to use free oxygen in their energy metabolism. In the urease test, both the isolates were not able to produce urease enzyme which was able to release ammonia and carbon dioxide. The ammonia then combines with carbon dioxide and hydrogen oxide to form ammonium carbonate which turned the medium alkaline, turning indicator phenol red from its original orange yellow color to bright pink. Therefore, a negative reaction was observed for urease test by the isolates (Fig. 3).

For arginine hydrolysis test, the isolates gave the yellow color indicating that they cannot produce ammonia from arginine. This might be due to the reason that organisms could not be able to use the amino acid arginine as a source of carbon and energy (Chris et al., 2006).

Both the isolates showed a positive response to the methyl red test. The isolates fermented the glucose to pyruvic acid and then use the mixed acid pathway to metabolize the pyruvic acid to other acids like lactic, acetic and formic acids to decrease $\mathrm{pH}$ below $\mathrm{pH}$ 4.4. At this $\mathrm{pH}$, the methyl red turned to red color, thus a positive reaction. The Voges-Proskauer test shows the negative correlation with the methyl red test and didn't show a positive reaction for VP test. This might be due to the inability of organisms to produce the acetylmethylcarbinol (acetoin) on the digestion of glucose.

Thus, both the isolates were Gram positive, non-motile, catalase negative and exhibited negative pattern of citrate utilization, $\mathrm{H}_{2} \mathrm{~S}$ formation, indole production, oxidase test, urease activity, $\mathrm{NH}_{3}$ production from arginine and VP reaction. These are the common characters of Lactobacillus species. These findings are also similar to those reported by Guessas and Kihal (2004). 


\section{Carbohydrate fermentation profile}

Interesting fermentation profiles were seen in table 2 for isolate A and B. According to the test results, both of the MRS isolates gave positive results with the fructose and lactose (Table 2).

There was no gas accumulation from glucose in the Durham tubes of isolate A, although the cultures were well grown. This result confirmed the homofermentative behavior of the isolate A. However, the noticeable gas bubbles were observed in Durham tubes of B isolate which showed facultative heterofermentative nature of isolate B. Acid production from glucose was observed in tubes of both the isolates.

The isolate A fermented lactose and fructose but not glucose (no gas production). Whereas, the isolate B fermented almost all the tested sugars viz. glucose, fructose, sucrose, lactose, maltose, mannitol, sorbitol and salicin except arabinose. This isolate B would likely be the Lactobacillus plantarum based on the result of sugar fermentation (Emanuel et al., 2005). On the other hand, isolate A fermented only three sugars out of nine which showed a narrow fermentation profile of isolate A. Thus, it would likely belong to Lactobacillus delbrueckii ssp. bulgaricus (Azadnia et al., 2011).

\section{Molecular identification}

The results obtained from Agharkar Research Institute, Pune was in conformance with those obtained by the biochemical characterization of isolates. Isolate A was supposed to be Lactobacillus delbrueckii ssp. bulgaricus and isolate B was considered as Lactobacillus plantarum.

\section{Microbial analysis of probiotic pomegranate drink}

The data related to microbiological analysis of probiotic drink is tabulated in table 3. In the present work, the count of beneficial bacteria was detected as $6.5 \times 10^{9} \mathrm{CFU} / \mathrm{mL}$ of drink. This count was in range for a product to be called as probiotic (Shah, 2001).

On the other hand, the yeast and mold count and coli-form count was also determined. And they were not detected in the sample, which showed that the product was free of any pathogenic microbes and safe for consumption.

\section{Acknowledgment}

The authors want to extend their gratitude to Prof. Umarikar, Department of Microbiology, Shivaji college, Parbhani for their valuable support and guidance.

\section{References}

Allameh, S.K., H. Daud, F.M. Yusoff, C.R. Saad, and Ideris, A. 2012. Isolation, identification and characterization of Leuconostoc mesenteroides as a new probiotic from intestine of snakehead fish (Channa striatus). African J. Biotechnol., 11(16): 3810-3816.

Azadnia, P., A. KhaleghBabaki, A.G.M. Shah, M. KarimiJashni, M.H. Zamani, and Taarof, N. 2011. Isolation and identification of Leuconostocs from traditional yoghurt in Tribes of Kazerun. J. Anim. Vet. Ad., 10(4): 552-554.

Chris, B., N. Paul, and Anthony, P.W. 2006. Food Microbiology and Laboratory Practices. Blackwell Publishing, State Avenue, USA.

Emanuel, V., V. Adrian, P. Ovidiu, and Gheorghe, C. 2005. Isolation of a Lactobacillus plantarum strain used for obtaining a product for the preservation of fodders. Afr. J. Biot., 4: 403- 408.

Forouhandeh, H. 2010. Isolation and phenotypic characterization of Lactobacillus species from various dairy products. Curr. Res. Bacteriol., 3(2): 84-88.

Guessas, B., and Kihal, M. 2004. Characterization of lactic acid bacteria isolated from Algerian arid zone raw goats' milk. African J. Biotechnol., 3(6): 339-342. 
Hawaz, E. 2014. Isolation and identification of probiotic lactic acid bacteria from curd and in vitro evaluation of its growth inhibition activities against pathogenic bacteria. African J. Microbiol. Res., 8(13): 1419-1425.

Hoque, M., F. Akter, K. Hossain, M. Rahman, M. Billah, and Islam, K. 2010. Isolation, Identification and Analysis of probiotic properties of Lactobacillus spp. from selective regional yoghurts. World $J$. Dairy and Food Sci., 5(1): 39-46.

Kalui, C.M., J.M. Mathara, P.M. Kutima, C. Kiiyukia, and Wongo, L.E. 2009. Functional characteristics of Lactobacillus plantarum and Lactobacillus rhamnosus from Ikii, a Kenyan traditional fermented maize porridge. Afr. J. Biotechnol., 8: 43634373.

Leisner, J.J., B. Pot, H. Christensen, G. Rusul, J. Olsen, B.W. Wee, K. Muhammad, and Ghazali, H.M. 1999. Identification of Lactic Acid Bacteria from Chili Bo, A Malaysian Food Ingredient. Appl. Environ. Microbiol., 65(2): 599-605.

Luckow, T., and Delahunty, C. 2004. Consumer acceptance of orange juice containing functional ingredients. Food Res. Int., 37: 805-814.

Markiewicz, L., and Biedrzycka, E. 2005. Identification of Lactobacillus and Bifidobacterium species with PCR applied to quality control of fermented dairy beverages. Polish J. Food and Nutrition Sci., 14(55): 359-365.

Mithun, S., V. Dipak, and Sheela, S. 2015. Isolation and identification of lactobacilli from raw milk samples obtained from Aarey milk colony. Int. J. Scientific and Res. Publications, 5(4): 1-5.
Negi, P.S., G.K. Jayaprakasha, and Jena, B.S. 2003. Antioxidant and antimutagenic activities of pomegranate peel extracts. Food Chem., 80: 393-397.

O'Shea, E.F., P.D. Cotter, C. Stanton, R.P. Ross, and Hill, C. 2011. Production of bioactive substances by intestinal bacteria as a basis for explaining probiotic mechanisms: Bacteriocins and conjugated linoleic acid. Inter. J. Food Microbiol., 152(3): 189-205.

Pelinescu, D.R., E. Sasarmaan, M.C. Chifiriuc, I. Staca, A.M. Nohita, I. Avram, F. Serbancea, and Dimov, T.V. 2009. Isolation and identification of some Lactobacillus and Enterococcus by a polyphasic taxonomical approach. Romaniun Biotechnol. Lett., 14: 42254233.

Ranadheera, R.D.C.S., S.K. Baines, and Adams, M.C. 2010. Importance of food in probiotic efficacy. Food Res. Int., 43: 1-7.

Samelis, J., F. Maurogenakis, and Metaxopoulos, J. 1994. Characterization of lactic acid bacteria isolated from naturally fermented Greek dry salami. Int. J. Food Microbiol., 23: 179-196.

Shah, N.P. 2001. Functional foods from probiotics and prebiotics. Food Technol., 55(11): 46-53.

Sharpe, M.E. 1979. Identification of the lactic acid bacteria. In: Identification Methods for Microbiologists. Skinner, F.A., and Lovelock D.W. (eds). Academic Press, London, pp. 233-259.

Tserovska, L., S. Stefanova, and Yordanova, T. 2002. Identification of lactic acid bacteria isolated from Katyk, goats milk and cheese. J. Cult. Collect., 3: 48-52.

\section{How to cite this article:}

Mamta Thakur, H.W. Deshpande and M.A. Bhate. 2017. Isolation and Identification of Lactic Acid Bacteria and their Exploration in Non-Dairy Probiotic Drink. Int.J.Curr.Microbiol.App.Sci. 6(4): 1023-1030. doi: https://doi.org/10.20546/ijcmas.2017.604.127 